\title{
RESILIENT STRUCTURE ASSESSMENT USING COBB-DOUGLAS PRODUCTION FUNCTION: THE CASE OF THE INDONESIAN METAL INDUSTRY
}

\author{
Ida Bagus Made Putra Jandhana ${ }^{1 *}$, Teuku Yuri M. Zagloel ${ }^{1}$, Rahmat Nurcahyo ${ }^{1}$ \\ ${ }^{1}$ Department of Industrial Engineering, Faculty of Engineering, Universitas Indonesia, Kampus UI \\ Depok, Depok 16424, Indonesia
}

(Received: April 2018 / Revised: May 2018 / Accepted: September 2018)

\begin{abstract}
The metal industry in Indonesia is facing greater risks and challenges locally and globally. Therefore, decision makers in this industry should be able not only to be competitive in the market but also to be resilient in this dynamic environment. The purpose of this study is to assess and analyze the resilience of the metal sector in Indonesia through the Cobb-Douglas Production Function (CDPF). The analysis shows how labor expenses, capital investment, and Total Factor Productivity (TFP) contribute to sector growth. Shock, represented by the drastic changes in both global and local economies reflected in exchange rate shocks in 2008 and 2013, impacts not only sector growth but also the composition of labor expenses, capital investment, and TFP in the sector. Based on time series data, this study determines that the assessment is able to detect the structure of the sector's production function, which becomes the building block of sector resilience after experiencing a shock. This study and its findings contribute to studies in resilience measurement in both the metal sector and other industries.
\end{abstract}

Keywords: Assessment; Cobb-Douglas Production Function; Resilience; Sector

\section{INTRODUCTION}

The metal sector is currently facing greater challenges not only due to its riskier and more complex operating environment but also due to its very competitive market. To maintain growth in this demanding environment, the sector must be resilient in facing various disruptions that may inhibit sector performance. One of many methods to analyze resilience is through assessing the growth of several variables described in Production Function theories, such as labor expenses, capital investment, and applied technology in production. Although there are other Production Function theories such as Constant Elasticity of Substitutions by Solow (1957) and Leontief Production Function by Leontief (1947), this research limits its investigation to exploring the use of the Cobb-Douglas Production Function (CDPF) by Cobb and Douglas (1928) as described by Baier et al. (2002).

Sector resilience is very important to national economies since it contributes to the sustainability of output for national economic growth (Mankiw, 2014). The resilience of the Indonesian metal sector had been tested over the past few decades. This includes a major financial crisis in 1997-1998, a global crisis in 2008, and local currency devaluation in 2013. The impact of these crises shows the weakness of the Indonesian economy and the importance of the industrial sector to the economy. Although there had been an increasing trend of average

*Corresponding author's email: putrajandhana@yahoo.co.id, Tel.+62214712241, Fax.+62214712241 Permalink/DOI: https://dx.doi.org/10.14716/ijtech.v9i5.1862 
annual economic growth of 5.1\% between 1999-2008 after experiencing the 2008 crisis, the growth of the industrial sector still shows a slowing trend with an average annual growth of $3.9 \%$ (Suryahadi et al., 2012).

Several studies have implemented resilience concepts in economics over the past few years. For example, Rose and Krausmann (2013), Kumar and Gregory (2013), and Dormady et al. (2018) elaborated on the framework for a resilience analysis of input-output production function at the firm level. These studies focused more on community resilience in disaster zones. Using the same framework as Dormady et al. (2018), this study proposes a different approach using CDPF to analyze and assess resilience at the sector level through its production structure when the sector experiences currency shock during an economic crisis. This paper adds to the previous study in assessing resilience by measuring the efficiency of the metal sector in Indonesia (Jandhana et al., 2017). Efficiency was measured by calculating the input and output of the metal sector and using the Data Envelopment Analysis (DEA) method. Despite its ability to assess industrial resilience through its efficiency value (Jandhana et al., 2017), this study found that DEA has several limitations. First, it is difficult to track the recovery trend in sector performance recovery and to trace the shift in input variables after the sector experiences economic shocks. Second, the input and output variables need to be analyzed prior to calculation so the results reflect the actual condition (Zbranek, 2013).

The concept of resilience has been implemented not only in economics fields but also in fields such as social sciences, environmental sciences, and others. Various definitions have been given (Kumar \& Gregory, 2013; Righi et al., 2015), but most are related to safety attitudes or responses to risk events such as shocks that impact or cause critical or catastrophic states. Additionally, they are also associated with adapting to new environments and returning to normal or equilibrium states. According to Windle (2011), the word "resilience" comes from the Latin word "resilire," which means "to leap back," "to spring back," or "to recover easily." Historically, several scholars have been considered pioneers in resilience studies. Holling (1973) introduced the implementation of both resilience and stability concepts to describe the behavior of ecosystems. Resilience was also used by Garmezy (1985) in the field of developmental psychology to describe the stress-resistant abilities of children. In the engineering field, resilience is implemented for safety measures (Woods, 2003). Several studies associated with resilience had been reviewed, such as recovery management after local disasters (Cutter et al., 2010), the ability of a person to regain mental or physical health despite adversity (Herrman et al., 2011), risk and performance management associated with supply chain resilience (Mandal, 2014), various system safety and risk assessment studies (Righi et al., 2015), and the concept development for the infrastructure resilience (Vugrin \& Camphouse, 2011).

There are two approaches to resilience studies in economics. The first approach is related to economic-based resilience, which describes how a local economy operates efficiently in a new equilibrium state after experiencing a shock by using its available resources. This concept was examined by Rose and Krausmann (2013). The second approach is engineering-based resilience, which was outlined by Bruneau et al. (2003). This engineering-based resilience focuses on investigating the properties of physical or social systems, such as robustness, redundancy, resourcefulness, and rapidity of response. Although the frameworks are helpful in providing guidance for analyzing the resilience characteristics of an object, they are not sufficient to analyze the structure of input-output production functions before and after an economic crisis.

Studies that investigate and assess industrial sector resilience through production function are still lacking. As described by Zagloel and Jandhana (2016), most performance-based indices 
such as the Global Competitive Index (GCI), World Competitiveness Yearbook (WCY), Competitiveness Industrial Performance (CIP), The Global Manufacturing Competitiveness Index (GMCI), and Purchasing Manager Index use Likert scales instead of employing methods that elaborate on the dynamic characteristics of sector resilience. The scale was also adopted to measure economic resilience by Briguglio et al. (2006). Although the Likert scale method has been applied in many performance assessments and measurements, the method may expose the studies to subjectivity by collecting biased answers if the questionnaires are not performed objectively by the surveyors (Hartley, 2013). In another study, Rose and Krausmann (2013) described the measurement framework for economic resilience in an area impacted by disasters. Although it did not explain any specific methods for measuring resilience at the sector level, the study suggested the use of a computable equilibrium model to measure economic resilience in the macro-economic setting. However, the computable equilibrium model is relatively difficult to trace and analyze (Taylor \& von Amin, 2006). Accordingly, they suggested that more studies are needed to explore other resilience assessments and measurements in the economic sector as it experiences disruptions. Furthermore, Righi et al. (2015) also argued that further research should be conducted on resilience measurement and assessment by implementing the Resilience Engineering (RE) platform in other field of studies.

With this background, this study concludes that there is a research gap for exploration of a quantitative assessment of resilience in industrial sectors. Accordingly, this study proposes a method to analyze how the exchange rate shock changes sector resilience by examining any changes in production function described by the Cobb-Douglas Production Function (CDPF), such as production factors, labor, capital, and TFP values. This investigation is also intended to become a building block for the future design of a resilience-based indices measurement in different industrial setups. This study contributes to the development of measurement engineering that will be employed in a decision analysis with risk consideration. This paper includes several theories related to resilience studies and CDPF, the measurement methodology, the results of the calculation, a result discussion, and a conclusion.

\section{METHODS}

As mentioned earlier, this study investigates resilience measurement in the metal sector through the analysis of CDPF. The CDPF theory was developed based on its assumption that marginal productivity is set statistically by the parameters in the production function theory that are based on both labor and capital utilization to produce manufactured goods (Bronfenbrenner, 1944). Although critics question the CDPF approach for its oversimplification of the complexity of production functions, Bhanumurthy (2004) argued that the function is still able to handle multiple inputs such as labor, capital, and productivity factors to generate the production output. Accordingly, CDPF theory has been used widely in various productivity-related studies in manufacturing industries and in inter-sector comparison studies to determine relative shares of labor and capital in total output. Therefore, this study formulates the framework of conceptual development in the resilience analysis and assessment, as shown in Figure 1.

The CDPF theory reflects the relationship between output, measured by Gross Domestic Product (GDP), and input, measured by the capital and labor involved in the production process. CDPF describes the relationship by estimating the regression coefficient based on the aggregate data and the parameters of the production functions as suggested by the NeoClassical Theory from economics (Biddle, 2012). CDPF can be formulated as follows:

$$
Y_{t}=A_{t} L_{t}^{\alpha} K_{t}^{\beta}
$$




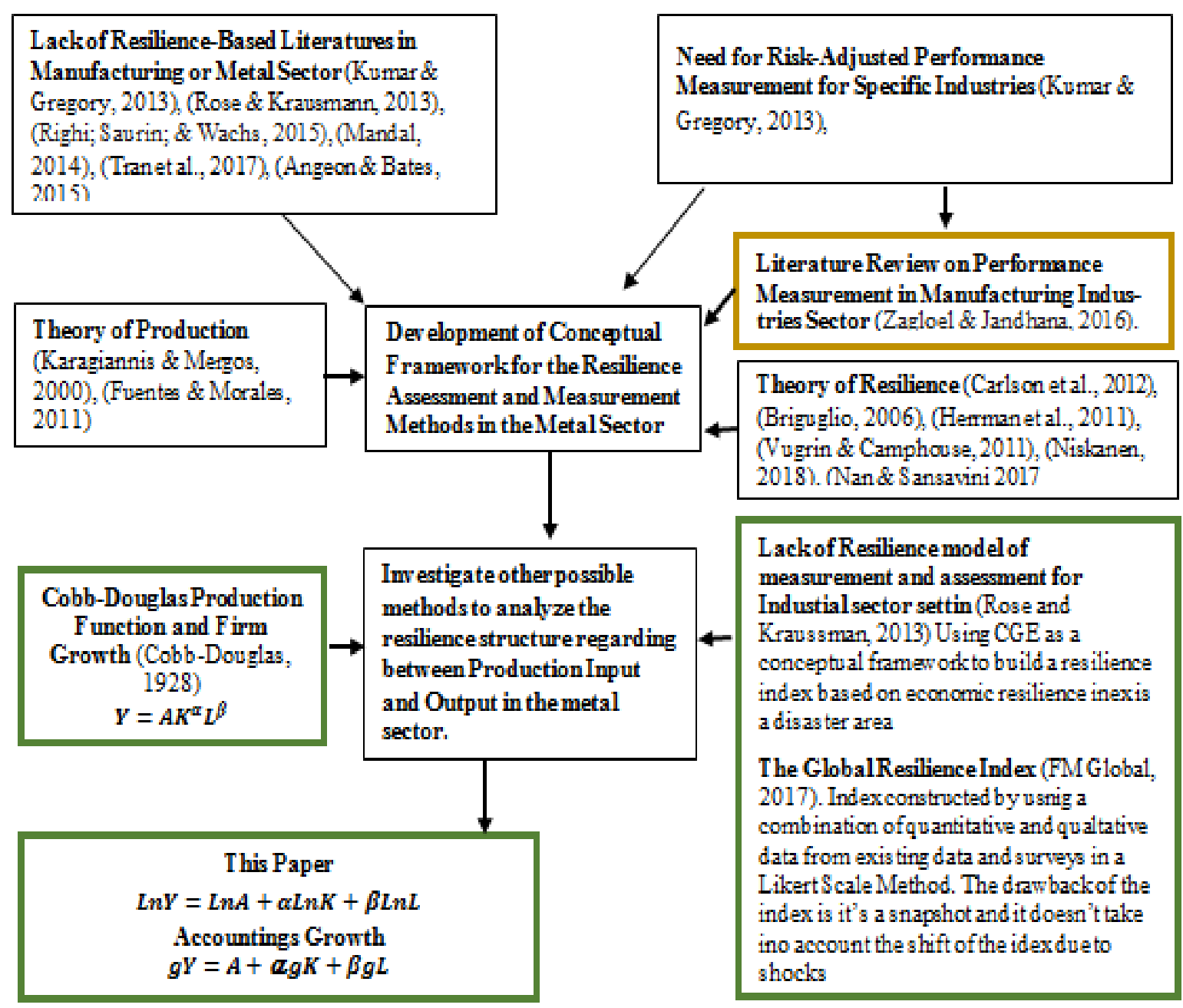

Figure 1 The development of resilience analysis using CDPF theory

where $Y$ is the output generated by metal industries, $L$ is the labor as production input measured in man-hours used in a year, $K$ is the capital as production input, i.e., machinery, tools, buildings, and others, $t$ is the year of production, $A$ is the TFP constant by applying technology of production, $\alpha$ and $\beta$ are the output elasticity constants from labor, capital, and the applied technology, in addition $A, \alpha$, and $\beta$ are constants that represent statistical estimation.

Furthermore, to determine which variable contributes significantly to the growth of the production factor output, a linear form of Equation 1 derives the Solow Residual (Solow, 1957) as follows:

$$
g_{Y}=g_{A}+\alpha_{1} g_{L}+\alpha_{2} g_{K}
$$

where $g_{y}$ represents the growth rate of $Y$, while $g_{A}, g_{L}$, and $g_{K}$ represent the growth rate of technology, labor, and capital, respectively. $\alpha_{1}$ is the elasticity value of labor toward output and $\alpha_{2}$ is the elasticity value of capital toward output. This research suggests a different angle of CDPF analysis compared to the study by Hallegatte (2014). As quoted by Driga (2015), Hallegatte (2014) focused on the use and changes of $\Omega k$, a term that describes the proportion of capital adjusted due to the crisis. In this study, both capital and labor are analyzed simultaneously by employing a dummy variable $D$ in the production function. $D$ is used specifically to verify and compare any changes in the output from Equation 1 both before and after the economic crisis, as follows: 


$$
\ln Y_{t}=\ln A_{t}+\alpha \ln L_{t}+\beta \ln K_{t}+\gamma \ln D_{t}+e_{t}
$$

where $D_{1}$ is defined as the dummy variable that indicates the period before the economic crisis between 2005 and 2008 and $D_{0}$ indicates the period after the economic crisis between 2009 and 2015. When the dummy variables show any significant changes, the CDPF formula will be exercised in those two periods to verify any structural changes in the input variables. To analyze the CDPF further before the crisis occurred between 2005 and 2008, let $t=0$. The resilience of the sector can be traced through the output recovery trend after the crisis by performing the following:

1. If $A_{1}=A_{0}$, then the values of TFP before and after the crisis are equal and the changes in labor and capital toward the output can be analyzed.

2. If $L_{1}=L_{0}$, then the values of labor expenses before and after the crisis are equal and the changes in TFP and capital toward the output can be analyzed.

3. If $K_{1}=K_{0}$, then the amount of capital invested in the sector before and after the crisis are equal and the changes in TFP and labor expenses toward the output can be analyzed.

In this study, various changes in labor expenses, invested capital, and TFP and their contributions to sector growth will be investigated by the followings steps:

1. Industrial manufacturing data surveyed by Indonesia Statistics between 2005 and 2015 are employed in the measurement. The survey covers 1,296 metal processing companies in Indonesia under ISIC 27, 28, and 29, including the total output of the metal sector, the amount of labor expenses, and the capital invested in the sector. The total output, labor expenses, and capital invested in the sector as well as income are presented in Rupiah.

2. All data are processed using the tools EVIEWS, SPSS, and EXCEL.

3. The estimated coefficient on each variable was validated through tests, such as autocorrelation, heteroscedasticity, multi-collinearity, and normality of errors.

4. The available annual data are transformed into quarterly data using the Cubic Spline Interpolation method to obtain the input for the calculation. The interpretation of the extrapolation process is still referred to as annual data.

5. The quarterly data are processed into the Cobb-Douglas function to determine the relationship between the output and input of labor $(L)$ and capital $(K)$ invested in metal industries by utilizing the assumption of Constant Returns to Scale.

6. The Cobb-Douglas function is then transformed into a linear function using the natural logs (ln) method as explained by Gelman and Hill (2006).

7. The impact of currency volatility between Rupiah and the U.S. dollar to the productivity growth of the metal sector was analyzed.

8. Any labor, investment, and TFP changes after the sector has experienced shock are evaluated both before and after by inserting a dummy variable into the model and employing a Solow Residual for further analysis.

The following section shows the results of the regression analysis in this research. The calculated estimation satisfies the basic assumption of the linear regression process in the CobbDouglas function.

\section{RESULTS AND DISCUSSION}

Based on the calculated data from 2005-2015, the result is summarized in the following formula:

$$
\begin{aligned}
& \ln (Y)=2.952+0.182 \ln (L)+0.818 \ln (K) \quad R^{2}=.97 \\
& (0.000)^{* * *}(0.000)^{* * *}(0.000)^{* * *}
\end{aligned}
$$


This result confirms that both labor and capital contribute significantly to the output of Indonesian metal industries under the assumption that $\alpha+\beta=1$ (Constant Returns to Scale). Based on the result described, the capital coefficient of 0.818 shows that $81.8 \%$ of the sector output depends on the capital invested toward production facilities. We assume that $\alpha+\beta \neq 1$, which means it may be a Decreasing or Increasing Return to Scale; the estimation result is shown in Table 1. The result also shows that the capital coefficient is 0.235 and labor coefficient is 0.234 . This means that between 2005-2015, for every $10 \%$ increment in capital invested in the sector, the output increases $2.35 \%$, and for every $10 \%$ increment in labor employed in the sector, there will be a $2.34 \%$ increase in output.

The global crisis in 2008 appears to have impacted sector performance. After the sector experiences a shock, the values of the contribution rate of both capital and labor in generating the sector outputs shift to a new equilibrium. This suggests that sector resilience weakened as the sector was exposed to risks of reduction in production process or increases in loan payment in the near future.

Table 1 Result summary of CDPF of metal industry sector, 2005-2015

\begin{tabular}{crccc}
\hline Period & In TFP & In Labor & In Capital & $\mathrm{R}^{2}$ \\
\hline $2005-2015$ & 4.571 & 0.234 & 0.235 & 0.73 \\
\hline & $(0.000)^{* * *}$ & $(0.000)^{* * *}$ & $(0.000)^{* * *}$ & \\
\hline $2005-2008$ & 7.469 & 4.532 & 4.858 & 0.80 \\
\hline & $(0.000)^{* * *}$ & $(0.000)^{* * *}$ & $(0.000)^{* * *}$ & \\
\hline $2009-2015$ & 5.509 & 0.754 & 0.136 & 0.84 \\
\hline & $(0.000)^{* * *}$ & $(0.000)^{* * *}$ & $(0.000)^{* * *}$ & \\
\hline
\end{tabular}

Note: 1. TPF (A) represents contribution toward sector output

2. *** represents $p$-value at $1 \%$ significant level

Between 2009 and 2015, as shown in Table 1, the TFP declined from $7.469 \%$ to $5.509 \%$. To observe the difference in sector performance before the crisis (between 2005 and 2008) and after (between 2009 and 2015), this research employs a dummy variable with the following result:

$$
\begin{gathered}
\ln (Y)=6.420+0.076 \ln (L)+0.735 \ln (K)-0.145 \ln (D) \quad R^{2}=.93 \\
(0.000)^{* * *}(0.000)^{* * *}(0.000)^{* * *}(0.000)^{* * *}
\end{gathered}
$$

In this research, there are findings generated from the exercise. First, as shown in Equation 5, there is a negative coefficient of the dummy variable $(-0.145)$, which indicates that there has been an output drop from the sector after the 2008 crisis compared to that generated before the crisis. As shown in Table 1, the value of the labor and capital coefficients on the Production Function shows a drop after the financial crisis of 2008 (all coefficients in 2009-2015 are lower than those in 2005-2008). Second, there is a positive coefficient of correlation between the sector output generated and the exchange rate Rupiah/U.S. dollar $(E R)$ variation $\left(\rho_{\mathrm{Y}, \mathrm{ER}}=0.89\right)$ and a positive coefficient of correlation between the amount of capital invested in the sector and ER variation $\left(\rho_{K, E R}=0.85\right)$. The positive coefficient of correlation suggests that there is a significant increase shown in the sector output generated as well as the amount of capital invested in the sector with the increased value of the U.S. dollar in Rupiah. This is contrary to the reduction in the amount of labor expenses shown by the coefficient of correlation between the amount of labor expenses and ER variation $\left(\rho_{\mathrm{L}, \mathrm{ER}}=-0.19\right)$. Furthermore, the statistical data taken from Indonesia Statistics suggests that there has been negative growth in sector output 
following the drop of Rupiah value after the crisis. Therefore, this research suggests that there should be more researches on the transfer mechanism of price shock toward production function. At this stage, this research would explain the changes in CDPF variables toward the output growth described in Table 2. Furthermore, CDPF assumes that technology $(A)$ remains constant (Solow, 1957) despite the technological changes applied in the production sector. Accordingly, this research uses the Accounting Growth Theory as explained by Solow (1957) and shown in Table 2.

Table 2 Result summary of growth function of metal industry sector $(g Y), 2005-2015$

\begin{tabular}{cccccc}
\hline Period & & Growth TFP & Growth Labor & Growth Capital & $\mathrm{R}^{2}$ \\
\hline 2005-2015 & Coefficient & 0.001 & 0.313 & 0.703 & 0.84 \\
\hline & p-value & $(0.000)^{* * *}$ & $(0.000)^{* * *}$ & $(0.000)^{* * *}$ & \\
\cline { 2 - 6 } & Share (\%) & 2.70 & 12.40 & 84.90 & \\
\hline $2005-2008$ & Coefficient & 0.001 & -0.026 & 0.704 & 0.87 \\
\hline & p-value & $(0.000)^{* * *}$ & $(0.000)^{* * *}$ & $(0.000)^{* * *}$ & \\
\cline { 2 - 6 } & Share (\%) & 3.11 & -1.19 & 98.08 & \\
\hline $2009-2015$ & Coefficient & 0.006 & -0.117 & 0.583 & 0.91 \\
\hline & p-value & $(0.000)^{* * *}$ & $(0.000)^{* * *}$ & $(0.000)^{* * *}$ & \\
\cline { 2 - 6 } Note: $* * *$ represents p-value at 1\% significant level & -5.66 & 85.92 & \\
\cline { 2 - 6 } & Share (\%) & 19.74 & & \\
\end{tabular}

This finding suggests that technology has been implemented in the metal sector at an average growth of $0.01 \%$ annually between 2005 and 2015. This also shows that the elasticity coefficient of labor is 0.313 , which means there is a $3.13 \%$ increase in output as the labor employed is increased $10 \%$. The elasticity coefficient of capital is 0.703 , which means there is a $7.03 \%$ increase in output as the capital investment is increased $10 \%$. This indicates that the increase of labor expenses may not yield the same margin of output in the near future. From Table 2, the average capital growth and labor growth were multiplied by their real growth to find the amount of contribution of labor, capital, and technology toward $100 \%$ growth of production output from the metal sector. Based on the computation using the model from Equation 3, the result also shows that the growth rate of output $g_{Y}$ was $3.7 \%$ between 2005 and 2015. This growth was supported proportionately: $2.70 \%$ by the growth of technology usage, $12.40 \%$ by the growth of labor employed, and $84.90 \%$ by the growth of capital invested in the sector. From this finding, it can be concluded that, in general, to increase sector resilience as indicated by sector growth, more capital needs to be invested to boost sector productivity.

Productivity, according to Almström and Kinnander (2011) from Tangen (2005), is defined as the output over input. The return of productivity after the sector has experienced a shock might be an indication of sector resilience. Figure 2 describes changes in sector productivity growth from 2005 to 2015 based on the output value over labor as well as the output value over capital utilized. Between 2005 and 2010, productivity growth in the Indonesian metal sector increased approximately $8.8 \%$ despite the slow growth of the global economy. Although the average national economy had been experiencing a weak trend since 2010 (Dutu, 2016), the growth of the metal sector increased to $28.7 \%$ between 2011 and 2015 .

De Menezes (2005) suggested that TFP may increase after experiencing shock because some companies may decide to improve productivity during downturns by rationalizing the amount of labor expenses, providing productivity improvement tools, and providing productivity training for the labor force. However, the growth of capital productivity shows a different profile. Between 2005 and 2015, the capital productivity only grew $0.18 \%$. Between 2012 and 2015 , the productivity of capital used showed negative growth. This negative trend suggests 
that, to survive the impact of currency shock, most companies in the metal sector changed their financial strategies to reduce operating and financial costs.

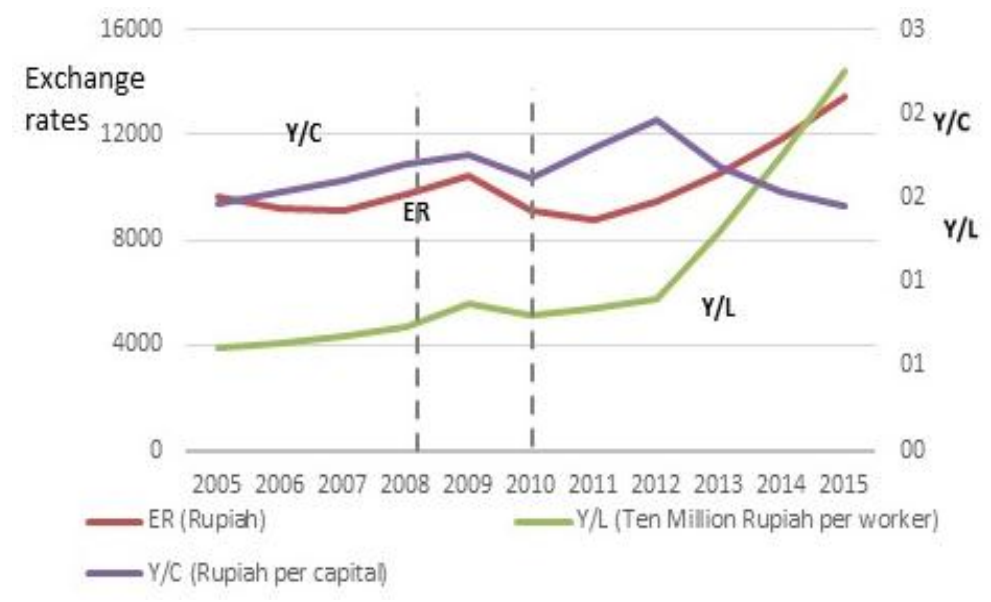

Figure 2 Output per labor employed (Y/L), Output per capital (Y/C) vs exchange rate (ER) movement 2005-2015

Finally, this study shows that a resilience assessment can be performed by analyzing the production function that supports sector growth. The changes in production function, represented by labor, capital, and TFP, were evaluated based on how they impact sector growth. The high coefficient values of both labor and capital suggest a dependency on high-skilled labor and technology in production process. This is parallel with governmental policies in many developed countries that invest more in highly technical jobs (Karabarbounis \& Neiman, 2014). Thus, to improve resilience, it is suggested that the sector improves its labor productivity and production technologies.

This exercise shows how a shock can be detected and assessed its impact toward the structure of the sector resilience. The shocks, which are represented by the drastic depreciation of Rupiah to the U.S. dollar in 2013, may not always have a negative impact in the long run. As the result shows, although there was a significant drop in labor productivity due to the global crisis in 2008 and a small dip in output in 2013, there has been a steady growth trend of labor productivity from 2013 forward. The result supports findings in a previous study on resilience measurement by the Data Envelopment Analysis approach (Jandhana et al., 2017). Both studies suggest that productivity improved while the industry was recovering from crisis. However, unlike the previous study, this study finds that the same trend does not occur for the capital invested in the sector. For the most part, Dutu (2016) suggested that this slow-down was caused by problems with regulatory reforms, such as low administrative capacity, long process of business licensing, increased minimum wage, and poor budget execution. To restore productivity growth, which is an indication of sector resilience, Dutu (2016) suggested a structural reform in the sector's production function by the government. Finally, in line with Dastkhan and Owlia (2009), this study argues that the concept and techniques of resilience measurement should serve as additional tools for policy makers to analyze business decisions at the sector and firm levels.

\section{CONCLUSION}

Resilience assessment helps decision makers analyze policies in the industrial sector and their associated risks. As discussed previously, this study proposes a method to analyze resilience in the metal sector in Indonesia by observing changes in production function. In this study, the Cobb-Douglas Production Function (CDPF) was employed to explore any variations in 
production factors, such as labor, capital, and TFP values, which were examined both before and after an economic crisis. By using the data series as the input of CDPF, the study shows that resilience in the Indonesian metal sector can be investigated and analyzed further. The result also shows that shock, represented by a change in exchange rate, impacts not only sector growth but also the composition of labor expense, capital investment, and TFP in the sector. This study found contradictory results in the analysis of the correlation between currency shock toward capital investment and sector output. This finding suggests that there is a need for further investigations on analyzing the impact of various shocks toward production function and developing its measurement method. In doing so, the result of this research will become a building block for future research in developing a resilience-based measurement for the industrial sector.

The study also suggests that the sector's resilience has improved as the industries are able to adapt to the new environment. Based on the findings, the drop in sector growth after the 2013 crisis was much shallower than the drop after the global crisis in 2008. Moreover, a positive trend in sector growth was seen after 2013. This study reflects an approximation of performance in the metal sector between 2005 and 2015, adjusted according to exchange rate shocks. This investigation did have some limitations, for example, labor expenses, capital investments, TFP, and exchange rate shocks were the only factors used to determine sector output. In reality, other factors also contribute to sector performance and the causes of shock that impact the sector. Nevertheless, the research findings are applicable to further studies of resilience capacity in other sectors.

\section{REFERENCES}

Allen, R.G.D, 1968. Macroeconomic Theory: A Mathematical Treatment. London: McMillan

Almström, P., Kinnander, A., 2011. The Productivity Potential Assessment Method: Assessing and Benchmarking the Improvement Potential in Manufacturing Systems at Shop-floor Level. International Journal of Productivity and Performance Management, Volume 60(7), pp. $758-770$

Baier, S., Dwyer G., Tamura, R., 2002. How Important are Capital and Total Factor Productivity for Economic Growth?. Federal Reserve Bank of Atlanta, Working Paper No. 2002-02

Bhanumurthy, K.V. 2004. Arguing a Case of Cobb-Douglas Production Function. Review of Commerce Studies. Delhi, India

Biddle, J., 2012. Retrospectives: The Introduction of the Cobb-Douglas Regression. Journal of Economic Perspectives, Volume 26(2), pp. 223-236

Briguglio, L., Cordina, G., Bugeja, S., Farrugia, N., 2006. Conceptualizing and Measuring Economic Resilience. Available online at www.researchgate.net, Accessed on May, 2016.

Bronfenbrenner, M., 1944. Production Functions: Cobb-Douglas, Interfirm, Intrafirm. Econometrica, Journal of the Econometric Society, Volume 12(1), pp. 35-44

Bruneau, M., Chang, S.E., Eguchi, R.T., Lee, G.C., O’Rourke, T.D., Reinhorn, A.M., Shinozuka, M., Tierney, K., Wallace, W., von Winterfeldt, D., 2003. A Framework to Quantitatively Assess and Enhance the Seismic Resilience of Communities. Earthquake Spectra, Volume 19(4), pp. 733-752

Cobb, C.W., Douglas, P.H., 1928. A Theory of Production. The American Economic Review, Volume 18(1), pp. 139-165

Cutter, S. L., Burton, C. G., Emrich, C. T., 2010. Disaster resilience indicators for benchmarking baseline conditions. Journal of Homeland Security and Emergency Management, Volume 7(1), pp. 1-24 
Dastkhan, H., Owlia, M.S., 2009. Study of Trends and Perspectives of Industrial Engineering Research. South African Journal of Industrial Engineering, Volume 20(1), pp. 1-12

de Menezes, A.G., 2005. Demand Shocks and Productivity Growth. Portuguese Economic Journal, Volume 4(1), pp. 15-45

Dormady, N., Roa-Henriquez, A., Rose, A., 2018. Economic Resilience of the Firm: A Production Theory Approach. Available online at www.researchgate.net, Accessed on May, 2016

Drigă, D.M., 2015. Formal Aspects of Resilience. Manager, Volume 22(1), pp. 322-328

Dutu, R., 2016. Why has Economic Growth Slowed Down in Indonesia? An Investigation into the Indonesian Business Cycle using an Estimated DSGE Model. Journal of Asian Economics, Volume 45, pp. 46-55

Garmezy, N., 1985. Stress-resistant Children: The Search for Protective Factors in Stevenson, $J E$ (ed.) Recent Research in Developmental Psychopathology, pp. 213-233

Gelman, A., Hill, J., 2006. Data Analysis using Regression and Multilevel/Hierarchical Models. Cambridge University Press

Hallegatte, S., 2014. Economic Resilience: Definition and Measurement. The World Bank

Hartley, J., 2013. Some Thoughts on Likert-type Scales. International Journal of Clinical and Health Psychology, Volume 13, pp. 83-86

Herrman, H., Stewart, D.E., Diaz-Granados, N., Berger, E.L., Jackson, B., Yuen, T., 2011. What is Resilience? The Canadian Journal of Psychiatry, Volume 56(5), pp. 258-265

Holling, C.S., 1973. Resilience and Stability of Ecological Systems. Annual Review of Ecology and Systematics, pp. 1-23

Indonesia Statistics, 2017. Available online at https://www.bps.go.id/ Accessed on November 17,2018

Jandhana, I.B.M.P., Zagloel, T.Y.M., Nurcahyo, R., 2017. Measuring Industrial Resiliency by using Data Envelopment Analysis Approach. In: 3rd International Conference on Business and Engineering Research (ICBER). Osaka, Japan 17th-18th November.

Karabarbounis, L., Neiman, B., 2014. The Global Decline of the Labor Share, Quarterly Journal of Economics, Volume 129(1), pp. 206-223

Kumar, M., Gregory, M., 2013. An Exploration of Risk Management in Global Industrial Investment. Risk Management, Volume 15(4), pp. 272-300

Leontief, W., 1947. Introduction to a Theory of the Internal Structure of Functional Relationships. Econometrica, Journal of the Econometric Society, Volume 15(4), pp. 361373

Mandal, S., 2014. Supply Chain Resilience: A State-of-the-art Review and Research Directions. International Journal of Disaster Resilience in the Built Environment, Volume 5(4), pp. 427-453

Mankiw, N.G., 2014. Principles of Macroeconomics. USA: Cengage Learning

Righi, A.W., Saurin, T.A., Wachs, P., 2015. A Systematic Literature Review of Resilience Engineering: Research Areas and a Research Agenda Proposal. Reliability Engineering \& System Safety, Volume 141, pp. 142-152

Rose, A., Krausmann, E., 2013. An Economic Framework for the Development of a Resilience Index for Business Recovery. International Journal of Disaster Risk Reduction, Volume 5, pp. 73-83

Solow, R.M., 1957. Technical Change and the Aggregate Production Function. The Review of Economics and Statistics, Volume 39(3), pp. 312-320

Suryahadi, A., Hadiwidjaja, G., Sumarto, S., 2012. Economic Growth and Poverty Reduction in Indonesia Before and After the Asian Financial Crisis. Bulletin of Indonesian Economic Studies, Volume 48(2), pp. 209-227 
Tangen, S., 2005. Demystifying Productivity and Performance. International Journal of Productivity and Performance Management, Volume 54(1), pp. 34-46

Taylor, L., von Amin, R., 2006. Modelling the Impact of Trade Liberalisation. A Critique of Computable General Equilibrium Models. Oxlam International Research Report, July 2006 Vugrin, E.D., Camphouse, R.C., 2011. Infrastructure Resilience Assessment through Control Design. International Journal of Critical Infrastructures, Volume 7(3), pp. 243-260

Windle, G., 2011. What is Resilience? A Review and Concept Analysis. Reviews in Clinical Gerontology, Volume 21(2), pp. 152-169

Woods, D.D., 2003. Creating Foresight: How Resilience Engineering can Transform NASA's Approach to Risky Decision Making. Work, Volume 4(2), pp. 137-144

Zagloel, Y., Jandhana, I.B.M.P., 2016. Literature Review of Industrial Competitiveness Index: Research Gap. In: Proceeding of Industrial Engineering and Operations Management (IEOM) Conference. Kuala Lumpur, Malaysia

Zbranek, P., 2013. Data Envelopment Analysis as a Tool for Evaluation of Employees' Performance. Acta Oeconomica et Informatica, Volume 16(1), pp. 12-21 